\title{
Issue Linkage, Delegation, and International Policy Cooperation*
}

\author{
Giancarlo Spagnolo \\ Churchill College, Cambridge, and \\ Stockholm School of Economics ${ }^{\dagger}$
}

This version: March 16, 1999

\begin{abstract}
How many international agreements should there be, and who should sign them? When policy issues are separable, linking them in a "grand international agreement" facilitates policy cooperation by reallocating slack enforcement power. When policy issues are substitutes, issue linkage further facilitates policy cooperation by increasing the amount of available enforcement power. The contrary happens when issues are complements. Then a better strategy can be to delegate policy issues to different independent national agencies. Constitutional rules that permit credible delegation to agents with different objectives than governments facilitate international cooperation by generating stronger credible threats. Implications for multilateral agreements are discussed.

Keywords: International agreements; Policy cooperation; Policy coordination; Crossborder spillovers; International institutions
\end{abstract}

J.E.L. classification: E61; F13; F42; H77

${ }^{*}$ I am grateful to two anonymous referees of this journal whose comments greatly improved the paper. Thanks also to Tore Ellingsen, Richard Friberg, Johan Lagerlöf, Björn Segendorff, Roy Radner, and Jörgen W. Weibull for useful comments on this or strictly related work, and to Partha Dasgupta and Giancarlo Gandolfo for encouragement and support at all stages of my research. Remaining errors are my own. Financial support from Consiglio Nazionale delle Ricerche and C.I.D.E.I./University of Rome "La Sapienza" (PostDottorato) is gratefully acknowledged.

${ }^{\dagger}$ Correspondence to: Department of Economics, Stockholm School of Economics, P.O. Box 6501, 11383 Stockholm, Sweden; telephone: 46-8-7369602; fax: 46-8-313207; e-mail: Giancarlo.Spagnolo@hhs.se 


\section{Introduction}

The process of "globalization" is making nations more interdependent than ever before. Higher interdependence means greater externalities of domestic policies imposed on neighbor countries. Greater cross-border spillovers imply an increased need for international policy cooperation.

It is well known that the sovereignty of nations implies that international agreements have to be "self-enforcing," that is, constructed so that each country finds it convenient to respect their requirements even in the absence of an international authority able to enforce them.

This paper addresses the following questions: What is the optimal design for a set of self-enforcing international policy agreements? Countries may benefit from cooperation on many different policy issues. Which issues should each international agreement regulate? In order to facilitate international cooperation should governments keep all policy issues under centralized control or should they delegate some of them to independent national agencies (e.g., central banks), which would then enter into direct international agreements with their counterparts abroad? In the second case, which issues should be delegated and which should stay under government control? Finally, are constitutional rules that allow governments to credibly delegate policy choices to independent agencies with different objectives (e.g., to "more conservative" central bankers) good or bad for international policy cooperation?

International trade cooperation is crucial to prevent nations from using beggar-thyneighbor protectionist policies. ${ }^{1}$ Uncoordinated monetary and fiscal policies may lead to suboptimal outcomes when international spillovers are substantial. ${ }^{2}$ Global environmental issues pose similar policy dilemmas, and international cooperation has also been called for on competition, development, agricultural, drug control, and other policies. ${ }^{3}$ Peace remains the most important public good in need of international cooperation. Many of these policy issues have, in their static structure, the features of an international Prisoner's Dilemma. Because countries face such policy dilemmas repeatedly in time, self-enforcing international agreements can be analyzed as equilibria of infinitely repeated policy games.

Supergames have been used, for example, by Bagwell and Staiger (1990), Hungerford (1991), Riezman (1991), and others to analyze free trade agreements (see Staiger 1995), by Canzoneri and Henderson (1991), Currie and Levine (1993), and others to study monetary policy cooperation, and by Barret (1994) and others for international environmental agreements. To my knowledge, all these models focused on a single policy dimension, therefore

\footnotetext{
${ }^{1}$ Johnson (1953), Robinson (1947), and Scitovszky (1942) are the classical references.

${ }^{2}$ The literature on monetary policy spillovers is huge; a useful introduction is Bryant (1995).

${ }^{3}$ For example, see Cooper (1994) for environmental policy, Scherer (1994) for competition policy, Peters and Stanton ed. (1991) for agricultural policy, Sachs (1987) for developement policy, Cepeda (1994) for drug control policy.
} 
they could not tackle the questions addressed here.

Recent contributions on "issue linkage" in international environmental agreements, for example, by Folmer, van Mouche and Ragland (1991), Carraro and Siniscalco (1993, 1995), and Cesar and de Zeeuw (1994), provide preliminary answers to some of the questions above. However, most of these analyses focus on static strategic situations, therefore they leave important aspects of self-enforcing international agreements unexplored.

The "real world" of international relations, on the other hand, seems dominated by the belief that keeping policy issues separate is the best route to international cooperation. ${ }^{4}$ Not only do we observe separate international agreements on trade, monetary, environmental, and defense policies; we even have separate agreements on, say, control of CFC emissions and protection of whales.

In what follows I argue that focusing on single policy issues is not always the best strategy to achieve international cooperation, ${ }^{5}$ and that when it is, governments should delegate policy control to independent specialized agencies.

I proceed by extending and applying to international policy agreements Bernheim and Whinston's (1990) and Spagnolo's (1996a) analyses of collusion in oligopolies with multimarket contact. The basic model is extremely stylized: two symmetric countries interacting simultaneously on several policy issues with the strategic structure of infinitely repeated Prisoner's Dilemmas.

I start under the assumption that international policy games are fully separable. Then the strategic structure is isomorphic to that of Bernheim and Whinston (1990), and the best strategy to achieve international cooperation is to link all policy issues into a "grand international agreement." When policy games are separable linking them cannot harm international cooperation, while it can facilitate it by allowing the optimal reallocation of slack enforcement power among policy issues. ${ }^{6}$

I then follow Spagnolo (1996a) by relaxing the assumption of separable policy games. When policy issues are substitutes, linking them makes punishments harder and deviations less valuable, thereby facilitating policy cooperation whether or not slack of enforcement power is available. When policy issues are complements the mechanism works the other way around, and issue linkage makes defections more valuable and punishments less costly. Then

\footnotetext{
${ }^{4}$ To make an example, a GATT/WTO rule discourages countries to use trade sanctions in one area as threats to enforce cooperation in unrelated trade areas.

${ }^{5}$ One sign that this may be the case is that the GATT/WTO rule mentioned in the previous footnote is not respected in its substance: trade agreements on some classes of goods are often accepted and respected only "in exchange" for the acceptance and respect of other agreements on different goods. In other words, there are international gains from trade that such a rule, if fully enforced, would not allow to be exploited.

${ }^{6}$ For "...facilitates cooperation" I will mean throughout the paper "...makes countries' incentive constraints for respecting any agreement less stringent," so that a larger set of agreements becomes sustainable at any given intertemporal discount factor, and any given set of agreements becomes supportable at lower discount factors.
} 
the effect on cooperation is ambiguous: issue linkage improves the allocation of international enforcement power, but it reduces the overall amount of it.

When two complement issues have a similar strategic structure the allocative gains from a linkage are small, and are dominated by the negative effect of the linkage on available enforcement power. Then keeping policy agreements separate by delegating decision power to different, independent national agencies with the same objectives as the government facilitates international policy cooperation by generating stronger credible threats.

A simple constitutional rule requiring any change of the delegation contracts (or of the delegates) to be subject to parliamentary approval is sufficient here to give full commitment value to delegation even when contract renegotiation is costless and information is complete.

Under such a constitutional rule, governments can also credibly delegate policy decisions to agents with an objective function different from their own, as in the work of Dolado et al. (1994) and Currie et al. (1996). However, contrary to these authors' results, I find that the opportunity to delegate policy choices to "more conservative" agents (e.g. central bankers) tends to facilitate international policy cooperation.

Finally, I relate the results to the literature on multilateral trade agreements by showing that Maggi's (1996) argument that trade diversion effects make punishments from multilateral agreements relatively stronger can be generalized to other policy issues, thus reinforcing the case for multilateralism.

In what follows I abstract from any "transaction," "bureaucratic," or "complexity" costs of issue linkage and delegation. Also, countries are modelled as monoliths, so I will use the words "country" and "government" as synonyms.

The model is presented in Section 2; Section 3 analyzes issue linkage; Section 4 discusses delegation; and Section 5 considers extensions and concludes. Proofs are in the appendix.

\section{A simple model}

I will work with an extremely stylized two-country infinite horizon model with $n$ policy issues. ${ }^{7}$ Because of international spillovers, at each point in time each policy issue presents the features of a Prisoner's Dilemma game. Time is discrete (to simplify notation we will avoid the time superscript wherever possible), the two identical countries are named A and $\mathrm{B}$, and the $n$ policy issues are indexed by the subscript $i, i \in\{1,2, \ldots n\}$. The one-period strategic interaction on each issue can be represented as a separate Prisoner's Dilemma in which each country can choose to cooperate $\left(C_{i}\right)$ or defect $\left(D_{i}\right)$. I let $G_{i}$ denote the one-shot Prisoner's Dilemma on policy issue $i$, and $G_{i}^{\infty}$ the infinitely repeated policy game which has

\footnotetext{
${ }^{7}$ The model can be extended to the case of $n$ countries and continuous policy instruments with no relevant change in the analysis. Also, games repeated a finite but uncertain number of periods lead to identical results since a constant probability of the game ending each period can be easily incorporated in the discount factor.
} 
$G_{i}$ as its stage game. In each period policy games $G_{1}-G_{n}$ are played simultaneously. The $i$-th one-shot policy Prisoner's Dilemma is characterized by governments' action space $\Theta_{i}^{h}=\left\{C_{i}, D_{i}\right\}, h \in\{A, B\}$, and "material" or "policy" payoff functions $\Pi_{i}: \Theta_{i} \rightarrow R^{2}$, where $\Theta_{i}=\Theta_{i}^{A} \times \Theta_{i}^{B}$, which generate the material payoff matrices:

\section{Country B}

$C_{i} \quad D_{i}$

$\begin{array}{cccc}\text { Country A } & C_{i} & X_{i}, X_{i} & Z_{i}, Y_{i} \\ & D_{i} & Y_{i}, Z_{i} & N_{i}, N_{i}\end{array}$

with $Y_{i}>X_{i}>N_{i}>Z_{i}$, and $Y_{i}+Z_{i}<2 X_{i}$. Material payoffs from all policy issues enter the government's continuous and twice differentiable static objective function $U=$ $U\left(\Pi_{1}, \Pi_{2}, \ldots, \Pi_{n}\right)$, with $\frac{\partial U(.)}{\partial \Pi_{i}}>0$ for every $i$. I let $\delta<1$ denote governments' intertemporal discount factor, so that in each period $t$ governments maximize the intertemporal welfare function $W=\sum_{\tau=t}^{\infty} \delta^{\tau-t} U^{\tau}$.

I abstract from problems connected to information asymmetries by assuming throughout the paper that countries have complete information on the history of each policy supergame.

I focus on symmetric stationary agreements sustained by stationary punishment strategies. I consider threats from unrelenting trigger strategies ("revert to the static Nash equilibrium forever if a deviation is observed") as they are the simpler "optimal punishment" strategies that keep countries at their security levels (see Friedman 1971, and Abreu 1986). Little would change in the analysis if the punishment phase would last a finite number of periods or if the more complex renegotiation-proof punishment strategies proposed by van Damme (1989) were adopted. ${ }^{8}$

I let $B_{i}$ denote the short-run benefit from defecting unilaterally from an agreement to cooperate in $G_{i}^{\infty}$, and $C_{i}$ the cost of defecting in terms of loss of future gains from cooperation, where

$$
B_{i}=U\left(\Pi_{1}, \ldots Y_{i}, \ldots, \Pi_{N}\right)-U\left(\Pi_{1}, \ldots X_{i}, \ldots, \Pi_{N}\right),
$$

and

$$
C_{i}=\frac{\delta}{1-\delta}\left[U\left(\Pi_{1}, \ldots X_{i}, \ldots, \Pi_{N}\right)-U\left(\Pi_{1}, \ldots N_{i}, \ldots, \Pi_{N}\right)\right] .
$$

An international agreement to cooperate only on one policy issue $i$ is supportable if $B_{i} \leq$ $C_{i}$. When two policy issues, say $j$ and $k$, are linked in a single international agreement, countries can use the "optimal punishment" of interrupting cooperation on both issues to deter deviations on any one issue, in which case if a country deviates it will do it on all issues

\footnotetext{
${ }^{8}$ These alternative strategies are equivalent to unrelenting trigger strategies as they also can do no better than keeping deviating players at their security levels.
} 
simultaneously (Bernheim and Whinston 1990). Then, cooperation on the linked issues is supportable if $B_{j, k} \leq C_{j, k}$, where

$$
B_{j, k}=U\left(\Pi_{1}, \ldots, Y_{j}, Y_{k}, \ldots, \Pi_{N}\right)-U\left(\Pi_{1}, \ldots, X_{j}, X_{k}, \ldots, \Pi_{N}\right),
$$

and

$$
C_{j, k}=\frac{\delta}{1-\delta}\left[U\left(\Pi_{1}, \ldots, X_{j}, X_{k}, \ldots, \Pi_{N}\right)-U\left(\Pi_{1}, \ldots, N_{j}, N_{k}, \ldots, \Pi_{N}\right)\right]
$$

\section{Issue linkage and international policy cooperation}

\subsection{Linking issues to reallocate "enforcement power"}

Linking policy agreements on different issues may foster international cooperation by improving the allocation of scarce international enforcement power. ${ }^{9}$ This argument can be fully developed within the simpler case of separable policy issues.

Assumption 1 Governments' objective function is linearly separable in the policy issues, i.e. $U=U_{1}\left(\Pi_{1}\right)+U_{2}\left(\Pi_{2}\right)+\ldots+U\left(\Pi_{n}\right)$.

This assumption keeps us within the standard model of multiple independent supergames developed by Bernheim and Whinston (1990). Under Assumption 1 governments maximize the additive intertemporal welfare function $W=\sum_{\tau=t}^{\infty} \sum_{i} \delta^{\tau-t} U_{i}\left(\Pi_{i}\right)_{i}^{\tau}$. Then, analyzing a (set of) policy game(s) we can abstract from what happens in the remaining policy games without any loss of generality. To link agreements on two policy issues, say 1 and 2, means that countries begin playing the two policy games as a single game $G_{1,2}$ whose strategy set $\Theta_{1,2}$ is the Cartesian product of the strategy sets in the two games, $\Theta_{1,2}=\Theta_{1} \times \Theta_{2}$, and whose static payoff function is $U_{1,2}=U_{1}\left(\Pi_{1}\right)+U_{2}\left(\Pi_{2}\right)$. We can now state the first result.

Proposition 1 Under Assumption 1, countries' ability to sustain cooperation is maximized when all $n$ policy issues are linked in a unique "grand international agreement."

With separable policy issues the linkage cannot have negative effects on the degree of international cooperation that countries can sustain. When cooperation cannot be supported

\footnotetext{
${ }^{9}$ Although - for the sake of clarity - in the rest of this paper I will stick to the terminology used in previous work on the subject, questions on "issue linkage" seem not well formulated. Two agents interacting strategically on several issues are naturally represented by a single game in which players' strategy sets include choices on all issues at stake. The separation between policy issues induced by separate international agreements (when credible) is an artificial restriction on players' strategy sets. Therefore, I think, the correct question is not whether or not to link some separate policy issues but whether or not to remove the artificial restrictions that split the strategic interaction between governments into several disjointed compartments.
} 
on all policy issues, countries will agree to cooperate on a subset of policy issues such that cooperation becomes supportable. On the other hand, countries support cooperation on the linked issues with the optimal punishment of interrupting cooperation on all issues if a deviation on any one issue occurs. Therefore, when expected gains from cooperation are large with respect to some policy issues and small with respect to others, the linkage facilitates policy cooperation by allowing the slack of expected gains from cooperation (of enforcement power) present in the first issues to discipline policy choices in the second issues.

\subsection{Issue linkage and the amount of "enforcement power"}

The international policy dilemmas we usually depict as single Prisoner's Dilemmas are seldom independent from other strategic interactions governments are involved in. In order to evaluate the effects of the possible interdependence between policy issues, I follow Spagnolo (1996a) by letting governments' evaluation of policy results from one issue depend on the results obtained from others.

Definition 1 Two policy issues $j$ and $k$ are substitutes (complements) when $\frac{\partial^{2} U\left(\Pi_{1}, \ldots, \Pi_{n}\right)}{\partial \Pi_{j} \partial \Pi_{k}}<$ $(>) 0$.

Now we can state what follows.

Proposition 2 Suppose any two policy issues are substitutes. Then, linking them in a single international agreement always facilitates policy cooperation on these issues.

When issues are substitutes a simultaneous interruption of cooperation on more policy issues is a relatively stronger threat because when countries do not cooperate on one issue they value relatively more cooperation on substitute issues. Conversely, the one-shot gains from the simultaneous defections on the linked substitute issues are less valuable to governments than the sum of the one-shot gains from the independent deviations. These two effects facilitate policy cooperation on the linked issues whether or not there is slack enforcement power. A Corollary follows straightforwardly from Proposition 2.

Corollary 1 Suppose that (i) $\frac{\partial B_{i}}{\partial \Pi k}=\frac{\partial C_{i}}{\partial \Pi_{k}} \forall i \neq k$, and (ii) there exists a set of issues $S$ such that $i$ and $j$ are substitute for any $i, j \in S$. Then in any optimally designed set of international agreements all issues in $S$ are linked in the same agreement.

If any two substitute agreements are not linked, linking them increases available enforcement power thus allowing policy cooperation to be supported on more policy issues or at lower discount factors. However, when $\frac{\partial B_{i}}{\partial \Pi k} \neq \frac{\partial C_{i}}{\partial \Pi_{k}}$ for some $i$ and $k$, cooperation on some issues generates wealth effects that may affect in different ways the terms of interaction 
on other issues. In this case nothing general can be said about the optimality of a set of agreements.

When policy issues are complements the mechanism works in the opposite direction. A simultaneous interruption of cooperation on more issues is a relatively weaker punishment, and a simultaneous deviation from cooperation makes short-run gains from deviating on each issue more valuable. Formally:

Corollary 2 When two policy issues $j$ and $k$ are complements it holds $B_{j, k}>B_{j}+B_{k}$ and $C_{j, k}<C_{j}+C_{k}$.

(The Proof is the converse of that of Proposition 2)

It follows that when policy issues are complements issue linkage has an ambiguous effect on international cooperation: on one side it facilitates it by allowing for a better allocation of the enforcement power between issues; on the other side, it hinders it by reducing the overall amount of available enforcement power.

\section{Delegation and policy cooperation}

\subsection{Delegation as separation of powers}

Corollary 2 suggests that when two complement policy issues are similar with respect to available enforcement power, so that allocative gains from a linkage are small, policy cooperation should be easier if governments could commit to treat the issues independently. One way to implement this commitment is to delegate decision power to different, independent national agencies. For simplicity I focus exclusively on the effects of "observable" delegation. ${ }^{10}$ Assume temporarily that the contract between governments and delegates is publicly observable and cannot be secretly renegotiated. Indeed, we can state what follows.

Proposition 3 Suppose two policy issues are complements and not too dissimilar with respect to available enforcement power. Then, delegating each issue to a different independent national agency with the same objectives than the government facilitates international policy cooperation on these issues.

When asymmetries in the strategic structure of the policy issues are small, slack enforcement power is scarce and the allocative gains from a linkage are dominated by the negative effect of the linkage on available enforcement power. Then, separation through delegation is the best way to policy cooperation.

\footnotetext{
${ }^{10}$ Early studies of delegation with observable contracts are Crawford and Varian (1979) and Sobel (1981) in bargaining, and Vickers (1985), Fershtmann and Judd (1987) and Sklivas (1987) in oligopoly.
} 
It is worth noting that previous work on delegation in bargaining, industrial organization, and macroeconomics focuses on a single issue and on static strategic interactions. In these literatures delegation of decision power has strategic effects only when it distorts the principal's objective function. In contrast, our multi-issue model shows that delegation has relevant strategic effects also when delegates and principals have identical objective functions.

\subsection{Is delegation a credible commitment device?}

Dewatripont (1988) and Katz (1991) have questioned the value of contractual precommitments such as delegation when there is complete information. Contracts are pieces of paper that can be renegotiated away when this is in the interest of the contracting parties. This issue has been recently brought up by McCallum (1995) and Jensen (1997) in the context of monetary policy delegation.

Although in the absence of exogenous renegotiation costs the intrinsic cost of bargaining on gains from renegotiation will still give some commitment power to a contract (e.g. Anderlini and Felli 1998), in two-party relations under perfect information secret renegotiation may reduce substantially the commitment value of delegation. However, this is much less so in the case of a government supported by a coalition of parties, or of a parliament, delegating policy decisions to an independent agency. First, a multiplicity of parties in the renegotiation process increases the complexity of bargaining, and consequently the intrinsic cost of renegotiation. Second, and independently of renegotiation costs, a parliament may make secret renegotiation impossible by introducing a constitutional rule that requires any change of the delegation contract (or of the delegate) to be subject to a parliamentary discussion and approval. ${ }^{11}$

To see how this works, consider our simple model and let governments be free to secretly renegotiate contracts with the independent agencies at any point in time under perfect information. Further, let us adopt the extreme assumption that there are neither exogenous nor intrinsic (bargaining) costs of renegotiation. Still, we can state what follows.

Proposition 4 Suppose secret renegotiation is possible and costless. If all countries introduce a rule that requires any change of delegation contracts (or of delegates) to be subject to parliamentary approval, delegation is credible and Proposition 3 holds unchanged.

This is so because in our model the only reason for a government to renegotiate delegation (or the rule that makes it credible) is to induce a deviation. As soon as renegotiation is observed, other governments or their delegates react optimally by also deviating, so that no short-run gain can be obtained by "simulating" a commitment. Therefore the simple

\footnotetext{
${ }^{11}$ This is the case, for example, of New Zealand's central banker's incentive scheme.
} 
constitutional rule above is sufficient to give full commitment value to delegation contracts even in the extreme case when renegotiation is costless and information perfect.

\subsection{Delegation as a threat}

Further insights can be derived from the model by also allowing for credible policy delegation to agents with a different objective function than their governments'. Then we can ask, more generally: are constitutional rules that confer commitment value to policy delegation good or bad for international policy cooperation?

Dolado et al. (1994) and Currie et al. (1996) have shown in two-stage models with (monetary) policy spillovers that governments' opportunity to delegate decisions may generate an additional international Prisoner's Dilemma. Each government may find it unilaterally optimal to choose a "more conservative" agent (e.g. central banker) in order to enjoy larger spillovers from other countries. When all governments can delegate, all chosen policy makers are too conservative and the original policy dilemma is worsened.

Fortunately, most policy spillovers are not "once-in-a-life-time" events and countries interact repeatedly in time. In an infinitely repeated policy game the effect of the opportunity to delegate turns out to be quite different. Let $\underline{Y_{i}}$ denote country $i$ 's welfare (national product, in the example of monetary policy) in a period in which all countries delegate a policy issue with international spillovers to "more conservative" agents, $Y_{i}$ denote welfare when credible delegation is not feasible but countries do not cooperate, $\overline{Y_{i}}$ denote welfare when countries cooperate and choose the globally optimal policies that internalize spillovers, and $\bar{Y}_{i}^{d}$ welfare when the country unilaterally deviates from an international agreement to choose globally optimal policies, where ${\overline{Y_{i}}}^{d}>\overline{Y_{i}}>Y_{i}>\underline{Y_{i}}$. Now one can state the following result.

Proposition 5 The opportunity to credibly delegate policy choices to "over-conservative" agents facilitates international policy cooperation.

The additional Prisoner's Dilemma induced by constitutional rules that make delegation credible worsens countries' situation in the absence of an international agreement (lowers their security levels), thereby strengthening the threat to revert to non-cooperative policies. Because gains from violating the agreement need not be affected by the opportunity to delegate, such opportunity unambiguously facilitates international policy cooperation.

\section{$5 \quad$ Extensions and conclusions}

\subsection{Delegates' incentives and policy cooperation}

In the working paper (1996c) I show that governments can further facilitate international cooperation by designing delegates' incentives so that their gains from defecting are reduced. 
For example, a delegation contract such that the delegate is paid a fixed per-period rent (a high wage, perquisites, etc.) as long as policy results are "satisfactory" and is replaced if the results become "bad," removes all the delegate's short-run incentives to defect from an international agreement that delivers satisfactory policy results. If all countries use this incentive scheme, international cooperation becomes sustainable at any level of the discount factor. Furthermore, governments cannot lose by delegating, as each delegate cooperates only if he observes that all governments delegated, and to defect a government must first renegotiate the contract with his delegate, which makes the defection observable and therefore unprofitable. ${ }^{12}$

\subsection{Multilateral versus bilateral cooperation}

A recent paper by Maggi (1996) analyzes multilateral trade cooperation in the presence of asymmetric trade relations. ${ }^{13}$ In a three-country model with separable trade relations Maggi demonstrates, among other things, that a multilateral approach facilitates international trade cooperation by allowing for "third-party sanctions." At the end of his paper the author also argues that a multilateral approach facilitates international cooperation even more when trade diversion effects are taken into account. These effects make threats weaker in bilateral relations, since each country can partially substitute trade with one partner with trade with the other.

The argument is close to that in Section 3.2, although here the multiplicity of relations affects incentives to deviate, along with the strength of the punishments. The simple model of Section 2 can be easily reinterpreted to show that whenever policy cooperation with one country is a (perfect or imperfect) substitute for policy cooperation with another, multilateral agreements facilitate international cooperation. For example, suppose there are three symmetric countries and a single policy issue, and that between each two countries the policy issue has the payoffs of the Prisoner's Dilemma in Section 2. Then, each country will respect a multilateral agreement if and only if $B_{i, j} \leq C_{i, j}$ - where the subscripts are now relative to the other two countries - while the necessary conditions for cooperation being sustainable in bilateral agreements are $B_{i} \leq C_{i}$ and $B_{j} \leq C_{j}$. By the proof of Proposition 2, when payoffs from policy cooperation with the two countries are substitutes it holds $B_{i, j}<B_{i}+B_{j}$ and $C_{i, j}>C_{i}+C_{j}$, and a multilateral framework always facilitates cooperation (whether or not there are asymmetries between the policy games).

\footnotetext{
${ }^{12}$ Indeed, cooperation between central bankers appears often more easily achieved than cooperation between governments. For a detailed discussion of this type of delegation contracts in (oligopolistic) supergames see Spagnolo (1996b).

${ }^{13}$ I am grateful to a referee of this journal who let me note the analogies with Maggi's work.
} 


\subsection{Concluding remarks}

To clarify how the results above may apply to real world situations, let me make a few examples. Monetary and fiscal policies are often considered complements: coordination of fiscal policy appears to make coordination of monetary policy more effective, and therefore more valuable to governments (e.g. McKibbin and Sachs 1991). Then, Proposition 3 suggests that - if strategic asymmetries are not too large - keeping the two issues separate by increasing central banks' independence might facilitate policy cooperation. The case for central banks' independence is reinforced by the arguments in Sections 4.3 and 5.1. Conversely, different issues in defense policy seem partial substitutes (for example, air and sea defense), in which case a comprehensive defense agreement should stabilize international cooperation. Consider trade and environmental policies. There is an enormous asymmetry in available enforcement power between these two (sets of) issues. This is due to free trade being an excludable good, which allows credible trade sanctions to be selective with regard to the deviant country, and therefore much stronger than environmental sanctions. Then, the allocative argument behind Proposition 1 should prevail: the model suggests that linking environmental agreements to trade or any other policy agreement with excludable gains from cooperation is the best way to international cooperation. 


\section{Appendix}

Proof of Proposition 1. Under Assumption 1 it holds $B_{i}=U_{i}\left(Y_{i}\right)-U\left(X_{i}\right)$ and $C_{i}=$ $\frac{\delta}{1-\delta}\left[U_{i}\left(X_{i}\right)-U_{i}\left(N_{i}\right)\right]$. When any two policy issues $j$ and $k$ are linked in a single international agreement, countries' "optimal punishment strategies" consist of reverting to the non-cooperative strategy on all policy issues after a deviation on any one issue. Given these punishment strategies, a country's optimal deviation is a simultaneous deviation on all issues. Then the benefit from defecting unilaterally from the linked agreement is $B_{j, k}=B_{j}+B_{k}$, the cost of defecting is $C_{j, k}=C_{j}+C_{k}$, and the linked agreement is sustainable if $B_{j}+B_{k} \leq C_{j}+C_{k}$. Suppose $B_{j} \leq C_{j}$ and $B_{k} \leq C_{k}$; then $B_{j}+B_{k} \leq C_{j}+C_{k}$ and the linkage does not affect countries' ability to cooperate (cooperation is supportable in any case). Suppose $B_{j}>C_{j}$ and $B_{k}>C_{k}$; then $B_{j}+B_{k}>C_{j}+C_{k}$ and the linkage does not affect countries' ability to cooperate (cooperation is not supportable in any case). Suppose $B_{j} \leq C_{j}$ and $B_{k}>C_{k}$; then if $B_{k}-C_{k} \leq C_{j}-B_{j}$ the linkage facilitates cooperation as policy cooperation becomes supportable on both issues, if $B_{k}-C_{k}>C_{j}-B_{j}$ the linkage leaves countries' ability to cooperate unaffected as again only policy cooperation on issue $j$ is supportable. An analogous argument applies when $B_{j}>C_{j}$ and $B_{k} \leq C_{k}$. Now consider the linked agreement between policy issues $j$ and $k$, and any third policy issue $l$. The same argument applies, so linking issue $l$ to the linked issues $j$ and $k$ either increases or leaves unchanged a government's ability to sustain cooperation. The same logic applies to all other issues, and the statement follows.

Proof of Proposition 2. I first state a simple lemma.

Lemma 1 Let $U(x, y): R \times R \rightarrow R$ be continuous, differentiable, and such that $U_{x}>0$, $U_{y}>0, U_{x x} \leq 0$ and $U_{y y} \leq 0$. Then, for every $x^{\prime}, x^{\prime \prime}, y^{\prime}, y^{\prime \prime}$, with $x^{\prime \prime}>x^{\prime}$ and $y^{\prime \prime}>y^{\prime}$,

$$
U_{x y}=U_{y x}<(>) 0 \Leftrightarrow U\left(x^{\prime \prime}, y^{\prime \prime}\right)-U\left(x^{\prime \prime}, y^{\prime}\right)<(>) U\left(x^{\prime}, y^{\prime \prime}\right)-U\left(x^{\prime}, y^{\prime}\right) .
$$

Proof. The inequality above is satisfied if $\frac{\partial\left[U\left(x, y^{\prime \prime}\right)-U\left(x, y^{\prime}\right)\right]}{\partial x}<(>) 0 \Leftrightarrow \frac{\partial U\left(x, y^{\prime \prime}\right)}{\partial x}<(>$ )$\frac{\partial U\left(x, y^{\prime}\right)}{\partial x}$ which is always satisfied when $U_{x y}<(>) 0$.

Now, when any two issues $j$ and $k$ are not linked in a single agreement cooperation can be sustained on both issues if $B_{j} \geq C_{j}$ and $B_{k} \geq C_{k}$, which necessarily imply $B_{j}+B_{k} \geq$ $C_{j}+C_{k}$. When issues are linked the condition is instead $B_{j, k} \geq C_{j, k}$. When policy issues are substitutes linking issues always facilitates cooperation since it is always $B_{j, k}<B_{j}+B_{k}$ and $C_{j, k}>C_{j}+C_{k}$. To verify this, substitute the definitions in $B_{j, k}<B_{j}+B_{k}$ and note that in order for cooperation to be simultaneously supportable on independent issues the independent deviations on each single issue must also be simultaneously deterred, so that we must set $\Pi_{j}=X_{j}$ in $B_{k}$ and $\Pi_{k}=X_{k}$ in $B_{j}$. Rearranging, one obtains

$$
U\left(\Pi_{1}, \ldots, Y_{j}, Y_{k}, \ldots, \Pi_{n}\right)-U\left(\Pi_{1}, \ldots, X_{j}, Y_{k}, \ldots, \Pi_{n}\right)<
$$




$$
<U\left(\Pi_{1}, \ldots, Y_{j}, X_{k}, \ldots, \Pi_{n}\right)-U\left(\Pi_{1} \ldots, X_{j}, X_{k}, \ldots, \Pi_{n}\right),
$$

which is satisfied by Lemma 1. Conversely, substitute the definitions in $C_{j, k}>C_{j}+C_{k}$ and note that because when issues are not linked punishments are not simultaneous we must set $\Pi_{j}=X_{j}$ in $C_{k}$ and $\Pi_{k}=X_{k}$ in $C_{k}$. Rearranging, one obtains

$$
\begin{aligned}
U\left(\Pi_{1}, \ldots, X_{j},\right. & \left.N_{k}, \ldots, \Pi_{n}\right)-U\left(\Pi_{1}, \ldots, N_{j}, N_{k}, \ldots, \Pi_{n}\right)> \\
& >U\left(\Pi_{1}, \ldots, X_{j}, X_{k}, \ldots, \Pi_{n}\right)-U\left(\Pi_{1}, \ldots, N_{j}, X_{k}, \ldots, \Pi_{n}\right),
\end{aligned}
$$

which, again, is satisfied by Lemma 1 .

Proof of Proposition 3. Consider two policy issues $j$ and $k$ on which cooperation is supportable with no slack enforcement power, i.e. such that $B_{j}=C_{j}$ and $B_{k}=C_{k}$. By Corollary 2 when $j$ and $k$ are complements $B_{j}=C_{j}$ and $B_{k}=C_{k}$ imply $B_{j, k}>C_{j, k}$. Then cooperation can be supported on both issues when the two policy games are played independently and in neither of them when they are linked. The functions $B_{h}$ and $C_{h}$ are differences of utility functions continuous in policy games' material payoffs, therefore they are also continuous in material payoffs. Then, by continuity, perturbing the material payoffs of both policy games around the original values one finds (infinite) sequences of other (symmetric and asymmetric) policy games for which $B_{j} \leq C_{j}, B_{k} \leq C_{k}$, and $B_{j, k}>C_{j, k}$. The statement follows from this together with the assumptions that delegation is credible and delegates are independent.

Proof of Proposition 4. Consider two symmetric countries and two complement policy issues $j$ and $k$ such that is $B_{j} \leq C_{j}, B_{k} \leq C_{k}$, and $B_{j, k}>C_{j, k}$. Suppose both governments have approved the rule in the statement of the proposition and have delegated control on the two issues to two independent agencies, and that cooperation is being sustained on both issues. Because $B_{j, k}>C_{j, k}$ each government would gain if it could renegotiate the delegation contract, take back control on the policy issues, and defect unilaterally on both issues. But since a parliamentary discussion is necessary for any renegotiation to take place, the agencies of the opponent country observe that renegotiation is taking place before renegotiation is complete and the deviation occurs. Observing the renegotiation process, the opponent government's agencies forecast the renegotiating government's deviation and react optimally by also deviating (as a strictly dominant strategy). It follows that renegotiation cannot lead to short-run gains from a unilateral defection, while it induces a loss of future gains from cooperation. Because renegotiation is never profitable, delegation is credible and the statement follows.

Proof of Proposition 5. When delegation is not feasible $C_{i}=\frac{\delta}{1-\delta}\left[\overline{Y_{i}}-Y_{i}\right], B_{i}=$ $\bar{Y}_{i}^{d}-\overline{Y_{i}}$, and each country $i$ is willing to respect an international policy agreement if $B_{i} \leq$ 
$C_{i}$. When credible delegation is feasible countries can still agree not to delegate along the cooperative equilibrium, so that their static best response function is not affected by the opportunity to delegate. Then the benefits from deviating from the international policy agreement are $B_{i}^{D E L}=\bar{Y}_{i}^{d}-\overline{Y_{i}}=B_{i}$. In the non-cooperative phase countries are now caught into the delegation Prisoner's Dilemma obtaining $\underline{Y_{i}}<Y_{i}$ each period. Then the cost of defecting from the agreement is $C_{i}^{D E L}=\frac{\delta}{1-\delta}\left[\overline{Y_{i}}-\underline{Y_{i}}\right]>C_{i}$, therefore $B_{i} \leq C_{i}$ is always more stringent than $B_{i}^{D E L} \leq C_{i}^{D E L}$. 


\section{References}

[1] Abreu, D., 1986, Extremal equilibria of oligopolistic supergames, Journal of Economic Theory 39, 191-225.

[2] Anderlini, L. and L. Felli, 1998, Costly bargaining and renegotiation, manuscript, St. John's College, Cambridge, and London School of Economics.

[3] Bagwell, K. and R.W. Staiger, 1990, A theory of managed trade, American Economic Review 80, 779-795.

[4] Barrett, S., 1994, Self-enforcing international environmental agreements, Oxford Economic Papers 46, 878-894.

[5] Bernheim, B.D. and M.D. Whinston, 1990, Multimarket contact and collusive behavior, Rand Journal of Economics 21, 1-26.

[6] Bryant, R.C., 1995, International Coordination of National Stabilization Policies, (Integrating National Economies: Promises and Pitfalls series, Brookings Institution, Washington, D.C.).

[7] Canzoneri, M.B. and D.W. Henderson, 1991, Monetary policy in interdependent economies: a game-theoretic approach, (Cambridge, Massachusetts, M.I.T. Press).

[8] Carraro, C. and D. Siniscalco, 1993, Policy coordination for sustainability: commitments, transfers and linked negotiations, Nota di Lavoro 63.93, Fondazione ENI 'E.Mattei', Milano.

[9] Carraro, C. and D. Siniscalco, 1995, R.\&D. cooperation and the stability of international environmental agreements, C.E.P.R. Discussion paper N. 1154.

[10] Cepeda, U.F., 1994, International cooperation and the war on drugs, in B.M. Bagley and W.O. Walker, Drug trafficking in the Americas (New Brunswick, Miami).

[11] Cesar, H. and A. de Zeeuw, 1994, Issue linkage in global environmental problems, Nota di Lavoro 56.94, Fondazione ENI 'E.Mattei', Milano.

[12] Cooper, R.N., 1994, Environmental and Resource Policies for the World Economy (Integrating National Economies: Promises and Pitfalls series, Brookings Institution, Washington, D.C.).

[13] Crawford, V. and H. Varian, 1979, Distortion of preferences and the Nash theory of bargaining, Economic Letters 3, 203-206. 
[14] Currie, D. and P. Levine, 1993, Rules, Reputation and Macroeconomic Policy Coordination (Cambridge University Press, Cambridge, UK).

[15] Currie, D., P. Levine and J. Pearlman, 1996, The choice of 'conservative bankers' in open economies: monetary regime options for Europe, The Economic Journal 106, 345-358.

[16] Dewatripont, M., 1988, Commitment through renegotiation-proof contracts with third parties," Review of Economic Studies 55, 377-90.

[17] Dolado, J., M. Griffith and A.J. Padilla, 1994, Delegation in international monetary games, European Economic Review 38, 1057-1069.

[18] Fershtman, C. and K.L. Judd, 1987, Equilibrium incentives in oligopoly, American Economic Review 77, 927-940.

[19] Friedman, J. 1971, A noncooperative equilibrium for supergames, Review of Economic Studies 28, 1-12.

[20] Folmer, H., P. van Moushe and S. Ragland, 1991, Interconnected games and international environmental problems, Environmental and Resource Economics 3, 313-335.

[21] Hungerford, T., 1991, GATT: A cooperative equilibrium in a non-cooperative trading regime?, Journal of International Economics 31, 357-369.

[22] Jensen, H., 1997, Credibility of optimal monetary delegation, American Economic Review 87, 911-921.

[23] Johnson, H.G., 1953, Optimum tariffs and retaliation, Review of Economic Studies 21, 142-153.

[24] Katz, M., 1991, Game-playing agents: Unobservable contracts as precommitments, Rand Journal of Economics 22, 307-328.

[25] Maggi, G., 1996 (rev. 1997), The role of multilateral institutions in international trade cooperation, Woodrow Wilson School Working Paper, Princeton University.

[26] McCallum, B.T., 1995, Two fallacies concerning central-bank independence, American Economic Review 85, 207-211.

[27] McKibbin, W.J. and J.D. Sachs, 1991, Global Linkages: Macroeconomic Interdependence and Cooperation in the World Economy (Washington, D.C., Brooking Institution). 
[28] Peters, G.H. and B.F. Stanton eds., 1991, Sustainable agricultural development: The role of international cooperation: Proceedings of the 21st International Conference of Agricultural Economists (Darmouth, Aldershot UK).

[29] Riezman, R., 1991, Dynamic tariffs with asymmetric information, Journal of International Economics 30, 267-283.

[30] Robinson, J., 1947, Beggar-my-neighbor remedies for unemployment, in Essays on the Theory of Unemployment, 2nd Edition (Basil Blackwell, Oxford); reprinted in Readings in the Theory of International Trade (George Allen and Unwin, London, 1950).

[31] Sachs, J., 1987, International policy coordination: the case of the developing country debt crisis, N.B.E.R. Working paper N. 2287.

[32] Scherer, F.M., 1994, Competition Policies for an Integrated World Economy, (Integrating National Economies: Promises and Pitfalls series, Brooking Institution, Washington, D.C.).

[33] Scitovszky, T., 1942, A reconsideration of the theory of tariffs, Review of Economic Studies 9; reprinted in Readings in the Theory of International Trade (George Allen and Unwin, London), 1950.

[34] Sklivas, S.D., 1987, The strategic choice of managerial incentives, Rand Journal of Economics 18, 452-458.

[35] Sobel, J., 1981, Distortion of utilities and the bargaining problem, Econometrica 49, 597-619.

[36] Spagnolo, G., 1996a, Multimarket contact, financial constraints and collusion: on extremal equilibria of interdependent supergames, Working Paper in Economics and Finance No. 104, Stockholm School of Economics (forthcoming in the Journal of Economic Theory).

[37] Spagnolo, G., 1996b, Ownership, control, and collusion, Working Paper in Economics and Finance No. 139, Stockholm School of Economics.

[38] Spagnolo, G., 1996c, Issue linkage, delegation, and international policy cooperation, Nota di Lavoro No. 49.96, Fondazione ENI "Enrico Mattei," Milano.

[39] Staiger, R.W., 1995, International rules and institutions for trade policies, in K. Rogoff and G. Grossman eds., Handbook of International Economics, Vol.III (Elsvier Science, Amsterdam). 
[40] van Damme, E., 1989, Renegotiation-proof equilibria in repeated Prisoner's Dilemma, Journal of Economic Theory 47, 206-217.

[41] Vickers, J., 1985, Delegation and the theory of the firm, Economic Journal 95 (Supplement), 138-147. 